\title{
A Novel Method for Designing Fifth-Generation District Heating and Cooling Systems
}

\author{
Marwan Abugabbara ${ }^{1 *}$, Jonas Lindhe ${ }^{1}$ \\ ${ }^{1}$ Department of Building and Environmental Technology, Division of Building Services, Lund University, Lund 22100 , Sweden
}

\begin{abstract}
District heating and cooling systems have been undergoing continuous development and have now reached the fifth-generation. In this innovative technology, connected buildings share local excess energy that otherwise would be wasted, which consequently reduces primary energy demands and carbon emissions. To date, the issue of implementing fifth-generation district systems on existing buildings has received scant attention, and our research addresses this challenging gap by proposing a novel method for designing these systems. We first explain the possible thermal interactions between connected buildings, and then present an analytical solution for the network energy balance, pipe design, and the prediction of fluid temperature under a fixed temperature difference control strategy. The analytical solution was validated against numerical simulations performed on 11 existing buildings located in Lund, Sweden using Modelica models. A diversity index metric between heating and cooling demands was also included in these models to assess the efficiency of the district system in the building cluster. The results from the analytical and numerical solutions were in complete agreement since Modelica is an equation-based modelling language. The developed models pave the way towards future investigations of different temperature control strategies and new business models that arise from the shift to the fifth-generation.
\end{abstract}

\section{Introduction}

The global population is expected to reach 9.7 billion by 2050 where up to $68 \%$ will reside in urban areas [1]. As a consequence of this increase in urbanisation, the number of households is expected to grow by $70 \%$ [2]. One of the major challenges for future urban areas is to efficiently supply buildings with the required thermal energy. District Heating and Cooling (DHC) systems are an effective technology and considered most feasible in urban areas with high heat density [3]. Compared to their counterparts, DHC systems have high resilience to integrating renewable energy sources that would increase energy efficiency and reduce carbon emissions.

District heating networks have been widely used since their first implementation in the 1860s in New York, USA. The latest figures show that there are about 80,000 district heating systems around the world with a total pipe length of about $600,000 \mathrm{~km}$ [4]. The European market has a share of 6,000 systems and a pipe length of $200,000 \mathrm{~km}$. According to Werner [4], district cooling networks were introduced at a later stage compared to district heating networks. The first district cooling network was realized in Hartford, USA in 1962 and in Hamburg, Germany in 1967. Due to their higher security of supply and low carbon emissions, the implementation rate of DHC networks exceeds $50 \%$ in some countries like in Denmark and Sweden.

The basic idea of district heating networks is to generate heat and supply it to connected buildings through distribution pipes. The heat generation usually happens at a central heat production plant, e.g., boilers or combined heat and power plant. A heat carrier, typically water, delivers the heat to the end customer through the pipe network. At the customer level, the heat is exchanged between two fluid streams. The first of these is the fluid in the distribution pipe and the second is the fluid that circulates heat to the different radiators inside the building. A similar mechanism applies to district cooling, but for the purpose of heat extraction. The technology has evolved through several generations in order to improve energy efficiency.

The first generation used steam as a heat carrier, which due to the risk of explosions was replaced by water and led to the inauguration of the second generation [5]. The water was delivered at a temperature of about $100{ }^{\circ} \mathrm{C}$ and had to be lowered when buildings started to become more energy efficient. The reduction of water temperature to $80^{\circ} \mathrm{C}$ marked the introduction of the third generation, which is also known as the Scandinavian district heating networks [4]. Due to problems with high thermal distribution losses, the fourth generation allowed a significant temperature reduction to about $50{ }^{\circ} \mathrm{C}$ without affecting the security of heat supply. Despite the high efficiency the fourth generation achieves, the network, nevertheless, has a centralized heat production and cannot provide simultaneous heating and cooling.

The fifth-generation district heating and cooling (5GDHC) system addresses the previous issues by offering the following two solutions. First, the network operates at temperatures close to the ground

\footnotetext{
* Corresponding author: marwan.abugabbara@hvac.lth.se
} 
temperature. Local heat pumps and chillers in each building modulate the temperature to the required levels. This results in lower distribution losses and facilitates network expansion due to decentralized heat production. The second solution is related to sharing local excess heat from one building to another. For example, chillers pump water from the network to provide cooling to the building. At the same time, they reject heat that is injected back to the network and shared with other buildings. This means that the water flows through a bidirectional pipe network that provides simultaneous heating and cooling.

In order to achieve the highest system efficiency, buildings connected to a 5GDHC network need to be balanced in terms of their requirements for simultaneous heating and cooling. Typical examples of buildings with heating demands are residential and service buildings. On the other hand, data centres require cooling throughout the year. Buildings with simultaneous requirements for heating and cooling are exemplified in hospitals. Most of the documented projects with 5 GDHC networks have been realised in Switzerland. Examples of these projects are ETH Zurich campus Hönggerberg [6] and Suurstoffi district in Rotkreuz [7]. Each of these networks connects different buildings with different heating and cooling demands, which makes it difficult to assess the efficiency of the system at the early design stage when a new project with different buildings is launched.

Thus, the need for a robust tool that identifies potential building clusters that can be connected to the 5GDHC networks becomes increasingly important, in light of the difficulty with the assessment. Previous work by Zarin Pass et al. resulted in the development of the metric diversity index for assessing promising building clusters [8]. We build on the work of Zarin Pass et al. by developing a Modelica-based tool for designing any 5GDHC network including the calculation of the diversity index. Modelica is being warmly received by the world community for modelling complex physical systems [9] and continues to show promising prospects within modelling of district energy systems [10].

The objective of this paper is to demonstrate a novel method for designing the 5GDHC systems. Section 2 of this paper presents the system architecture, the analytical solution for designing the system, and a case study comprising eleven buildings. Section 3 illustrates and discusses the results of the simulations performed on the case study. Finally, conclusions and future work are outlined in Section 4.

\section{Method}

The design of 5GDHC systems can depend on different strategies and several system configurations. This section describes the developed design method for 5GDHC systems with installed heat pump and chiller at the building level. Firstly, the system components and thermal interactions between connected buildings are described. Secondly, an analytical solution is proposed to enable modelling the system using the equation-based
Modelica language. Thirdly, an assessment metric for clustering buildings is introduced. Lastly, a case study is presented in order to implement the design method and validate the analytical solution.

\subsection{System architecture and thermal interactions}

To throw more light on the different thermal interactions between connected buildings in a fifth-generation district heating and cooling network, consider the depicted building cluster in Figure 1. In this example, three buildings are connected to the network: a data centre building with only cooling demands; a residential building with only heating demands; and an industrial or a hospital building with simultaneous demands for heating and cooling. Each building extracts and/or rejects heat from/to the network according to its requirement for thermal energy. The substation room denoted as SR contains the installed heat pump (HP) and chiller $(\mathrm{CH})$ that modulate the temperatures to the required supply levels. These components can be replaced by a combined cool- and heat pump in other system configurations. In this study, we present a system with separate heat pump and chiller for the production of heating and cooling, respectively. The network can be easily expanded to connect more buildings in an urban area. The last component in the network is the balancing unit (BU) that is responsible for injecting heat to the network in the case of heat deficit, or discharging heat out from the network in the case of excess heat.

From Figure 1 we may elicit the following three main scenarios of thermal interactions taking place in the network. The first scenario considers buildings with only heating demands, such as the residential building. Here, the building requires heating that is first delivered by any rejected heat from other buildings connected to the network $\left(\mathrm{Q}_{\mathrm{rej}}\right)$. If these are absent, the balancing unit injects the required heat to the network and the residential building extracts it from the network $\left(Q_{e x t}\right)$. In the second scenario the process of delivering only cooling is described herein, as in the data centre building. The chiller in the building's substation room produces the required cooling, which results in a heating by-product in the chiller's condenser side. This heating is rejected to the network and distributed to other buildings that require heating. If such demands for heating in other buildings cease to exist, the energy is stored inside the balancing unit.

The third scenario can adapt different design configurations depending on the type of the installed heating and cooling units. We present the case where a heat pump and a chiller are both installed at the building level. In this scenario, simultaneous heating and cooling are required in the building, such as in the industrial building. Depending on whether heating or cooling is dominant, the corresponding heat pump or chiller delivers the required energy. The heat pump and chiller are connected at the inlets and outlets in order to exchange energy between them, as shown in the magnifying glass in Figure 1. The extracted or rejected 


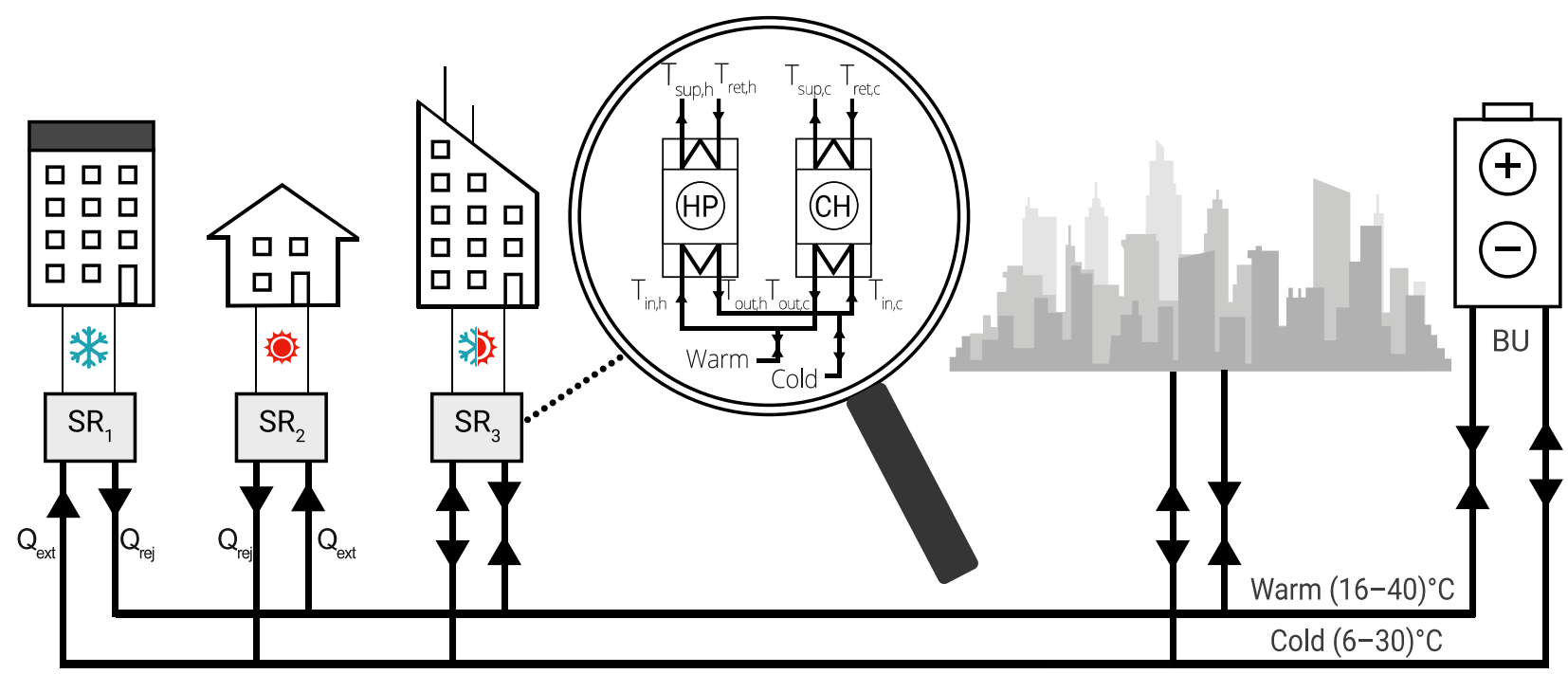

Fig. 1. Illustration of an abstract building cluster in a fifth-generation district heating and cooling system. SR denotes the substation room, BU represents the balancing unit, $Q_{\text {ext }}$ and $Q_{\text {rej }}$ refers to the extracted and rejected heat, while $T_{\text {sup,h }}, T_{\text {ret,h }}, T_{\text {sup,c, }}$, and $T_{\text {ret, }}$ represents the space heating/cooling supply and return temperatures. $T_{i n, h}, T_{o u t, h}, T_{i n, c}$, and $T_{\text {out,c }}$ describe the inlet/outlet temperatures in the heat pump and chiller.

energy is then derived as explained in scenario 1 and 2 , depending on the dominant category. In case the rejected energy to the network exceeds the capacity of the balancing unit, cooling towers are installed to discharge the heat from the network. As more buildings become connected to the network, the previous laws ofconservation are repeated until the sum of all flows of energy at a certain point in the closed network is equal to zero.

\subsection{Analytical solution}

To enable modelling and simulation of 5GDHC systems using the equation-based Modelica language, an analytical solution has been developed and is presented thoroughly in this section.

\subsubsection{Network energy balance}

A typical fifth-generation district heating and cooling network reaches an energy balance according to the synergetic thermal interactions between the connected buildings and the balancing unit. The energy balance is achieved through the following three stages: 1) intrabalancing, 2) inter-balancing, and 3) network balancing. These stages are explained below together with their mathematical derivation.

Stage 1. The heating and cooling demands for an individual building are balanced against each other. The building can have either a separate heat pump and chiller to provide heating and cooling, or a combined cool- and heat pump that provides simultaneous heating and cooling at the evaporator and condenser sides, respectively. The design principle for the two strategies is the same. As mentioned earlier, this paper presents the case where a separate heat pump and chiller are installed in the substation room.
For a building with heating and cooling demands denoted as $Q_{h}$ and $Q_{c}$, only one unit between the heat pump and the chiller is first operated independently. The electrical power $P_{e l}$ is then calculated as shown in Equation 1, where COP is the coefficient of performance of the operated unit.

$$
P_{e l}=\min \begin{gathered}
Q_{h} / C O P \\
Q_{c} /(C O P-1)
\end{gathered}
$$

The heating power at the condenser side $P_{h}$ and the cooling power at the evaporator side $P_{c}$ of the operated unit are derived in Equations 2 and 3.

$$
\begin{gathered}
P_{h}=P_{e l} \cdot C O P \\
P_{c}=P_{e l} \cdot(C O P-1)
\end{gathered}
$$

In an ideal scenario, the building's heating and cooling demands are balanced against each other at this stage. If the delivered heating and cooling power from the operated unit do not match the building demands, the remaining required heating or cooling are provided from the other buildings connected to the network and described in the next stage.

Stage 2. The balancing between the connected buildings occurs at this stage. The remaining heating requirement for an individual building $Q_{h, r e q}$ is described as the difference between the building heat demands and the heating power provided by the operated unit, as shown in Equation 4.

$$
Q_{h, r e q}=Q_{h}-P_{h}
$$

At this point, the heat pump provides the required heating by extracting heat $Q_{\text {ext }}$ that is pumped at the heat pump evaporator side. The extracted heat is represented in Equation 5 as follows:

$$
Q_{\text {ext }}=Q_{h, r e q}-\left(Q_{h, r e q} / C O P\right)
$$


Similarly, the required cooling demands for an individual building are represented in Equation 6.

$$
Q_{c, r e q}=Q_{c}-P_{c}
$$

The chiller provides the required cooling and, simultaneously, rejects excess heat from its condenser side into the network. The rejected excess heat $Q_{r e j}$ is represented as:

$$
Q_{r e j}=\frac{Q_{c, r e q}}{C O P-1} \cdot C O P
$$

If the total extracted heat is not equal to the rejected heat from all connected buildings, a final balancing stage is therefore required.

Stage 3. A network balancing unit is employed and has primarily two functions. First, it injects energy to the network in case the total extracted heat by the connected buildings exceeds the available energy in the network. This energy can be delivered from an energy source such as air-source or ground-source heat pumps. The quantity of injected energy $Q_{i n j}$ is equivalent to:

$$
Q_{i n j}=Q_{e x t}-Q_{r e j}
$$

Conversely, when the total rejected heat from the connected buildings are greater than the extracted heat, the balancing unit finally exhausts the excess energy out from the network. The exhausted energy $Q_{\text {exh }}$ is represented in Equation 9 as follows:

$$
Q_{\text {exh }}=Q_{\text {rej }}-Q_{\text {ext }}
$$

\subsubsection{Pipe design}

In order to size the branch warm and cold pipes at each building, the following analytical solution has been developed. The evaporator cold side of the heat pump represents the extracted energy and is connected to the cold pipe. This configuration can be seen in the illustration presented in Figure 1. The mass flow rate in the cold pipe $\dot{m}_{c o l}$ is defined as:

$$
\dot{m}_{\text {col }}=\frac{Q_{\text {ext }}}{C_{p, \text { water }} \cdot \Delta T}
$$

Similarly, the mass flow rate in the warm pipe $\dot{m}_{\text {war }}$ is defined as:

$$
\dot{m}_{w a r}=\frac{Q_{r e j}}{C_{p, w a t e r} \cdot \Delta T}
$$

The diameter of the cold and warm pipes can now be determined as described in Equations 12 and 13.

$$
\begin{gathered}
D_{c o l}=\sqrt{\frac{4\left(\frac{\dot{m}_{c o l}}{\rho \cdot v}\right)}{\pi}} \\
D_{w a r}=\sqrt{\frac{4\left(\frac{\dot{m}_{w a r}}{\rho \cdot v}\right)}{\pi}}
\end{gathered}
$$

\subsubsection{Fluid temperature}

The mass flow rates in the cold and warm pipes determine the change of the network fluid temperature. The fluid temperature decreases when energy is extracted from the network. On the contrary, the temperature increases when heat is rejected into the network. The network temperature is controlled and bound between low and high temperature limits. The decreasing temperature $T_{d e c}$ is defined as:

$$
T_{\text {dec }}=\left\{\begin{array}{l}
\max \left(T_{\text {fluid }}-\frac{\Delta T \cdot \dot{m}_{\text {col }}}{\text { Volume }}, T_{\text {low }}\right) \text { if } \dot{m}_{\text {col }}>0 \\
0 \text { otherwise }
\end{array}\right.
$$

where $T_{\text {fluid }}$ is the grid temperature and assumed equal to $T_{\text {low }}$ at the start of simulation, Volume is the total grid volume in $\mathrm{m}^{3}$ including pipes and the storage tank, $T_{\text {low }}$ is the pipe network lowest controlled temperature.

Analogously, the increasing temperature is controlled according to the highest network temperature $T_{\text {high }}$ and is described as:

$$
T_{\text {inc }}=\left\{\begin{array}{l}
\min \left(T_{\text {fluid }}+\frac{\Delta T \cdot \dot{m}_{\text {war }}}{\text { Volume }}, T_{\text {high }}\right) \text { if } \dot{m}_{\text {war }}>0 \\
0 \text { otherwise }
\end{array}\right.
$$

The fully mixed fluid temperature is then derived as:

$$
T_{\text {fluid }}=\max _{T_{\text {inc }}}
$$

The previous analytical solution presented in Section 2.2 was validated against numerical simulations performed in Modelica, where the results of the simulations are presented in Section 3 .

\subsection{Assessment metric}

Fifth-generation DHC systems are deemed only feasible when there is simultaneous demands for heating and cooling within the building cluster. The ratio between heating and cooling determines the amount of heat flow shared between buildings. Such a ratio can be derived using the diversity index suggested by Salat [11] and used in a previous study by Zarin Pass et al. [8] to search for promising building clusters in an urban environment. The diversity index for a building cluster varies between 0 and 1 , where 1 is complete balance of diversity and 0 is complete dominance of one category. Let $C$ be the number of categories and $P_{i}$ is the frequency of occurrence of each category $i$, the diversity index div can then be derived as follows:

$$
\operatorname{div}=\frac{C}{C-1}\left[1-\sum_{i=1}^{C} P_{i}^{2}\right]
$$

In a building cluster there are typically two categories of thermal demands, namely, heating and cooling. An ideal balance between heating and cooling depends on the heating coefficient of performance $C O P_{\text {heat }}$. For a system with direct free cooling, as shown in the connection between the heat pump and chiller in Figure 1, ideal thermal balance occurs when: 


$$
Q_{c}=Q_{h}\left(1-\frac{1}{C O P_{\text {heat }}}\right)
$$

where $Q_{c}$ and $Q_{h}$ denotes the respective building cooling and heating demands. The hourly diversity index $d i v_{h}$ can now be determined between heating and cooling categories in a cluster of buildings with $n$ number of buildings by combining Equations 17 and 18 and reformulating them as:

$$
\begin{array}{r}
d i v_{h}=2\left[1-\left(\frac{\sum_{i=1}^{n} Q_{c}}{\sum_{i=1}^{n} Q_{c}+\sum_{i=1}^{n} Q_{h}\left(1-\frac{1}{C O P_{\text {heat }}}\right)}\right)^{2}\right. \\
\left.-\left(\frac{\sum_{i=1}^{n} Q_{h}\left(1-\frac{1}{C O P_{\text {heat }}}\right)}{\sum_{i=1}^{n} Q_{c}+\sum_{i=1}^{n} Q_{h}\left(1-\frac{1}{C O P_{\text {heat }}}\right)}\right)^{2}\right]
\end{array}
$$

To facilitate the assessment of potential building clusters, an annual average of the hourly diversity div annual is weighted by the total hourly energy use in the cluster and expressed as:

$$
\operatorname{div}_{\text {annual }}=\frac{\sum_{h=1}^{8760} \operatorname{div}_{h}\left|Q_{\text {tot }, h}\right|}{\sum_{h=1}^{n}\left|Q_{\text {tot }, h}\right|}
$$

where $h$ represents the hour, 8760 is the total number of hours in a year, and $\left|Q_{t o t, h}\right|$ is the absolute sum of magnitude of all heating and cooling demands in a given hour with positive sign for both heating and cooling.

\subsection{Case study}

The developed analytical solution was validated numerically using Modelica simulations. The simulations involved sizing a 5GDHC network connecting 11 buildings located in Lund, Sweden. The map of the buildings is shown in Figure 2 together with the location of the balancing unit that consists of an airsource heat pump and a thermal energy storage implemented as a cylindrical water accumulator. The annual energy demands in the facility are 11 and $4 \mathrm{GWh}$ for heating and cooling, respectively. The total floor area of the buildings is about $110,000 \mathrm{~m}^{2}$ with different space use for offices, labs, conferences, restaurants, and a sport centre. The pipe network is currently under construction and the installation is progressing in different construction phases. The map in Figure 2 shows the completed construction phase one represented by the dashed red line. All buildings will be connected to the network at the end of the construction work.

The network design parameters for the reference design case are shown in Table 1. The parameters can be later adjusted in order to optimise both the design and the operation of the network. At the initial design stage, it was assumed that the 5GDHC network will operate simultaneously next to the traditional district system that is already connected to the buildings. The traditional system covers the domestic hot water demands and the peak loads that exceed the capacity of the heat pumps and chillers. The benefit of this approach is the significant reduction in investment costs. When the heat pumps and chillers are sized with a capacity of about

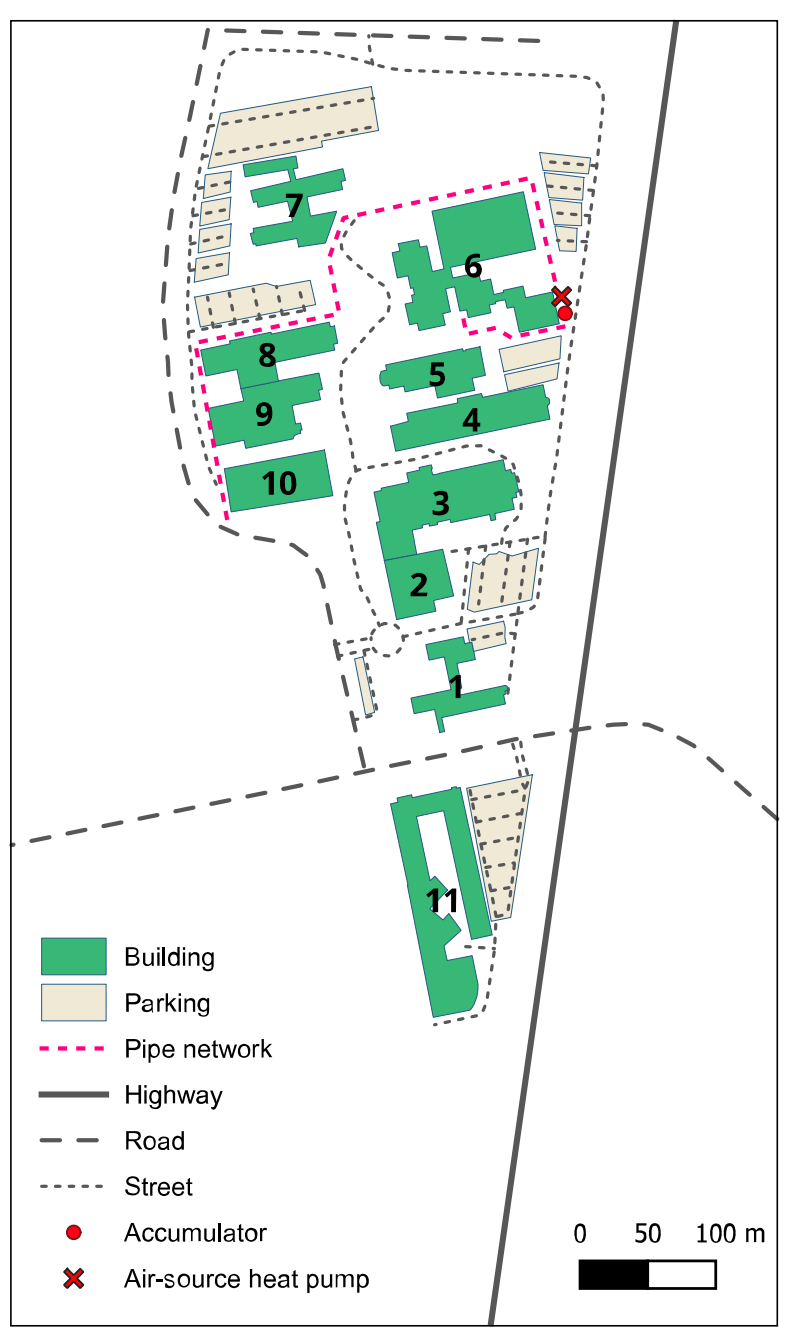

Fig. 2. Map of the eleven buildings included in the case study. The map was created using QGIS program for the analysis of geospatial data.

half the building's peak loads, the 5GDHC network covered 89 and $93 \%$ percent of the annual heating and cooling energy, respectively. By maintaining the connection between the buildings and the traditional district system, a security of supply is ensured throughout the year, while keeping the network investment cost minimal. Another design assumption was to consider the demands in building 10 as an archetype of building 7 . Building 10 was under construction and the acquisition of measured or simulated data was not possible. Since buildings 10 and 7 have almost the same space use and type of operation, this assumption allows to include the new building's demands in the design of the network.

Table 1. Design parameters for the reference case.

\begin{tabular}{lll}
\hline Parameter & Value & Unit \\
\hline Network temperature difference $(\Delta T)$ & 10 & $\mathrm{~K}$ \\
Network lowest temperature & 6 & ${ }^{\circ} \mathrm{C}$ \\
Network highest temperature & 40 & ${ }^{\circ} \mathrm{C}$ \\
Fluid maximum velocity & 1 & $\mathrm{~m} / \mathrm{s}$ \\
Storage tank volume & 150 & $\mathrm{~m}^{3}$ \\
\hline
\end{tabular}



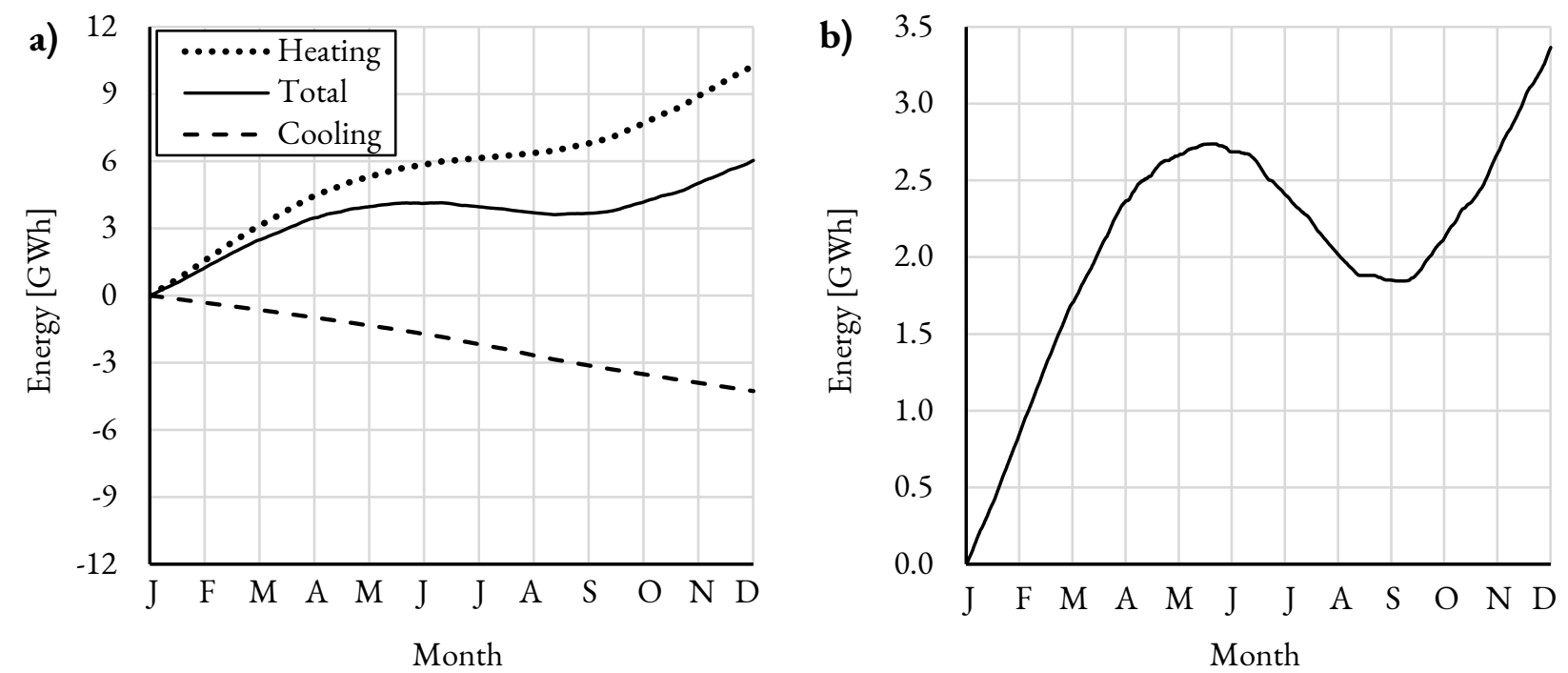

Fig. 3. Cumulated energy demands in the building cluster (a), cumulated energy provided by the balancing unit (b).

\section{Results and discussion}

The validation of the analytical solution and the results of the Modelica simulations performed on the case study are presented in this section. Because the behaviour of physical models developed in Modelica is described by differential algebraic equations, the results from the Modelica simulations were in complete agreement with the analytical solution. The annual Modelica simulations were performed using the DASSL integration algorithm with a $10^{-4}$ tolerance. The energy demands and the detailed analysis of the diversity index are introduced in section 3.1. The network fluid temperature is then presented with a discussion on the effect of a fixed temperature difference control strategy.

\subsection{Energy balance and load diversity}

Referring to the case study described in Section 2.4, the cumulated energy demands in the cluster including all eleven buildings are shown in Figure 3(a). As is evident, the cluster has simultaneous demands for heating and cooling throughout the year. The cooling demands are increasing steadily as represented in the dashed line. On the other hand, the dotted line shows that the demands for heating are lowest during summer. The summer demands for heating are used only for space heating since the demands for hot tap water were not included in this study. The annual energy demands in the cluster are about 11 and $4 \mathrm{GWh}$ for the respective heating and cooling. The simultaneous requirement for heating and cooling increases the potential for more load diversity within the cluster where energy can be shared within and between the buildings throughout the year.

The cumulated annual energy provided by the balancing unit is shown in Figure 3(b). To enhance appearance, note that the two figures do not have a uniform scale. Figure 3(b) provides an understanding of the energy balance in the cluster. Comparing these two figures, it can be seen that the balancing unit continuously injects energy to the network during the cold season when the demands for heating exceed the demands for cooling, as seen in the positive slope of the line in Figure 3(b). Conversely, when cooling demands dominate during the summer season, the network is charged with excess heat that results from the cooling process. In this case, the balancing unit starts to discharge the excess heat out from the network, which is represented by the negative slope of the line during summer. To increase the efficiency of the system, the amount of excess heat should be minimised. This can be realised by analysing the load diversity in each building in order to assess how each building contributes to the different demands for heating and cooling.

Figure 4 shows the contours of the diversity index for each building individually and when the building is paired, i.e., clustered, with only one other building. At first glance, one can see that there are three kinds of building combinations that have no diversity at all and are coloured in dark blue. These are buildings 3, 8 and the cluster combining these two buildings. Whilst these

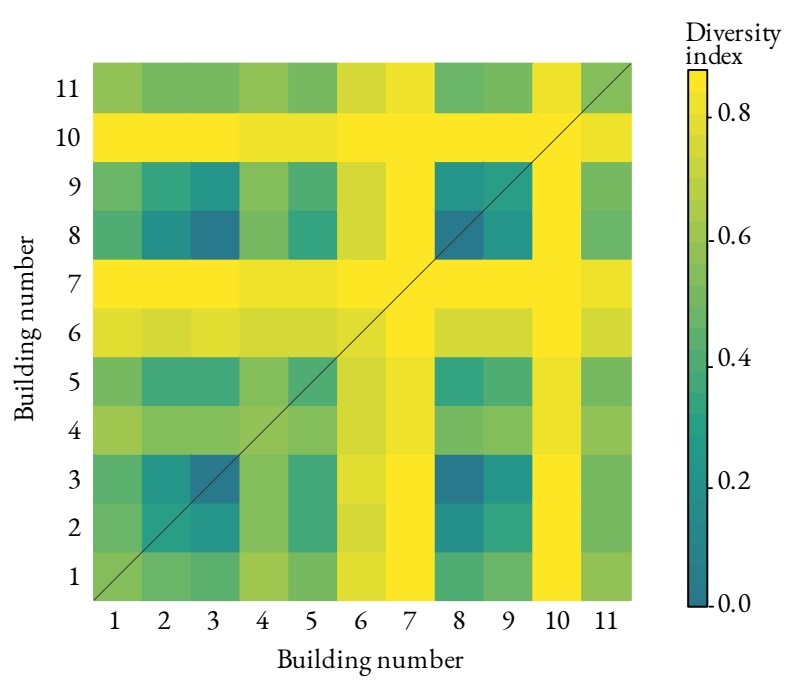

Fig. 4. Symmetric contour map of the diversity index for the individual buildings. 
results indicate zero load diversity, they do not reveal much about whether heating or cooling is the dominant category. At the other end of the spectrum, buildings 7 and 10 prove to serve as efficiency gains since the diversity index was improved in all their possible cluster combinations. As reported in [8], district systems are also built for the purpose of increasing community resilience and not only efficiency. For this purpose, we carried out a sensitivity analysis on the effect of each individual building on the diversity of the cluster covering all eleven buildings. The analysis not only considered the building as one block, but also considered whether heating or cooling demands are excluded from being covered by the network.

Figure 5 demonstrates the effect of excluding certain parts of the building on the diversity index. The annual diversity index for the cluster including both heating and cooling for the eleven buildings was 0.78 . Due to the dominant cumulated demands for heating throughout the year, excluding heating in an individual building yields a better load diversity within the cluster. On the contrary, excluding cooling demands has more negative consequences on the diversity between loads. Once again, the results confirm the importance of some buildings on the performance of the system. Excluding buildings 6,7 , and 10, especially their cooling demands, plummeted the annual diversity five times lower than the average of the other buildings. This result opens the possibilities for more flexible scenarios during the early design of 5GDHC systems. Instead of connecting buildings to the network as one block, only one category of thermal demands can be supplied by the network to maximise its efficiency. The excluded part of thermal demands can be covered by local auxiliary systems.

The analysis of the diversity index does not provide insights on how different clusters can be formed by the same number of buildings. A tool that can perform exhaustive searches through combination and permutation of buildings is required in order to a assess the impact of several clustering possibilities.

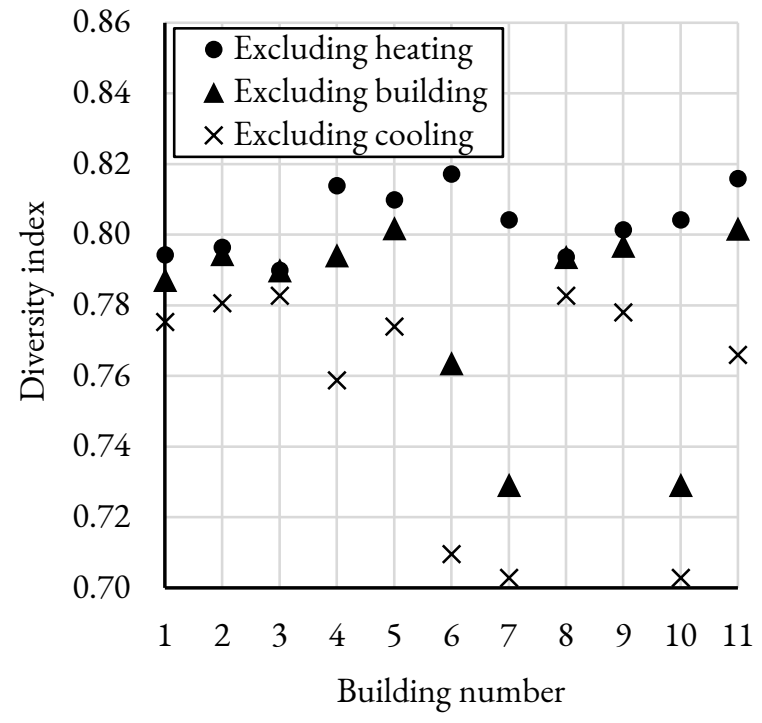

Fig. 5. Variations of the diversity index for different design scenarios. Annual diversity index for the cluster including all eleven buildings is 0.78 .

\subsection{Fluid temperature oscillation}

The fluid temperature oscillation in the pipes shown in Figure 6 provides an explanation of the different thermal processes happening in the system. For instance, the buildings extract energy from the network during cold months due to the dominant requirements for space heating. In spring, the requirements for space cooling starts to dominate, causing the buildings to inject energy to the network, which in return causes the network temperature to rise. At this point, the thermal storage tank starts to accumulate the excess energy and stores it for later use. As the demands for cooling keep rising during summer months, the network temperature reaches its maximum design temperature, and the tank reaches its maximum storage capacity. When the excess energy can no longer be utilised, the balancing unit discharges it out from the network. This process can also be seen by comparing Figure 6 with the negative slope of the line in Figure 3(b). Both charts confirm that the excess energy is not utilised between June and midAugust. A consideration of the temperature oscillation indicates that the network temperature is cold in winter when it is supposed to be warm, and it is warm in summer when it is supposed to be cold. This confirms the findings in [12] where a free-floating temperature of the warm line setpoint produced a similar behaviour. The authors in [12] attempted to optimise the warm line setpoint temperature in order to increase the performance of the heat pumps due to the dominating heating in winter. The different temperature control strategies require further research during the future development of the model developed in this study.

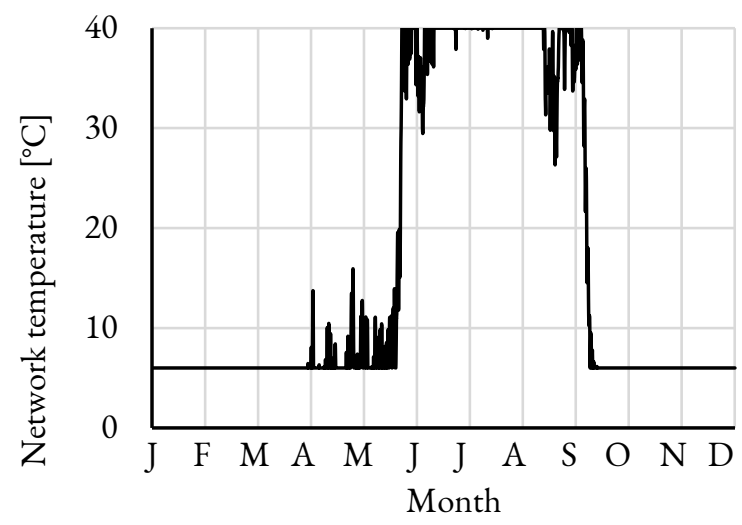

Fig. 6. Hourly fluid temperature oscillation in the pipes throughout the year.

\section{Conclusions}

The current study demonstrated a novel method for designing any fifth-generation district heating and cooling system. The models used for the design were developed using the Modelica language and they are under continuous improvement. We utilised the models to cluster eleven buildings located in Lund, Sweden and presented the different thermal interactions taking a place in the cluster. An analytical solution was developed and validated against the numerical Modelica simulations. The diversity index was also evaluated in 
the models for each individual building and for the cluster combining all buildings in order to understand and improve the diversity between heating and cooling demands.

From the analysis carried out on the case study, we conclude the following three main points. First, fifthgeneration district heating and cooling systems can be implemented in existing buildings to cover a primary base load of up to $90 \%$ of the annual heating and cooling demands. The peak loads are covered by conventional heating and cooling systems with minimal annual operating hours. The advantages of this approach are the reduced investment cost, the added flexibility in network expansion, and the ability to connect buildings with different low and high temperature requirements. Second, fifth-generation district systems allow covering only one side of the building's heating or cooling demands from the network. Such configuration can increase the system efficiency whilst it opens possibilities for new business models. Third, future work requires the investigation of different temperature control strategies, such as a free-floating setpoint of the warm or cold pipeline.

\section{Nomenclature}

$Q \quad$ Heating or cooling demand [W]

$P \quad$ Thermal or electrical power [W]

$\dot{m} \quad$ Mass flow rate $[\mathrm{Kg} / \mathrm{s}]$

$\Delta T \quad$ Temperature difference [K]

$D \quad$ Diameter $[\mathrm{m}]$

$\rho \quad$ Water density $\left[\mathrm{kg} / \mathrm{m}^{3}\right]$

$v \quad$ Fluid velocity $[\mathrm{m} / \mathrm{s}]$

\section{References}

[1] United Nations, "World population prospects: the 2017 revision, key findings and advance tables," Dep. Econ. Soc. Aff. PD, Ed. New York United Nations, 2017.

[2] P. IEA, "Energy technology perspectives 2012: Pathways to a clean energy system." International Energy Agency Paris, 2012.
[3] S. Amiri and G. Weinberger, "Increased cogeneration of renewable electricity through energy cooperation in a Swedish district heating system - A case study," Renew. Energy, vol. 116, pp. 866-877, 2018.

[4] S. Werner, "International review of district heating and cooling," Energy. 2017.

[5] M. Pellegrini and A. Bianchini, "The innovative concept of cold district heating networks: A literature review," Energies, vol. 11, no. 2, 2018.

[6] “Anergy grid ETH Zurich.” [Online]. Available: https://ethz.ch/en/the-ethzurich/sustainability/campus/environment/ener gy/anergy-grid.html. [Accessed: 15-May2020].

[7] A. Prasanna, V. Dorer, and N. Vetterli, "Optimisation of a district energy system with a low temperature network," Energy, vol. 137, pp. 632-648, 2017.

[8] R. Zarin Pass, M. Wetter, and M. A. Piette, "A thermodynamic analysis of a novel bidirectional district heating and cooling network," Energy, vol. 144, pp. 20-30, 2018.

[9] P. Fritzson, Principles of object-oriented modeling and simulation with Modelica 2.1. IEEE, 2004.

[10] M. Abugabbara, S. Javed, H. Bagge, and D. Johansson, "Bibliographic analysis of the recent advancements in modeling and cosimulating the fifth-generation district heating and cooling systems," Energy and Buildings, vol. 224. Elsevier Ltd, 01-Oct-2020.

[11] S. Salat, F. Labbé, C. Nowacki, and G. Walker, Cities and Forms: on sustainable urbanism. 2011.

[12] F. Bünning, M. Wetter, M. Fuchs, and D. Müller, "Bidirectional low temperature district energy systems with agent-based control: Performance comparison and operation optimization," Appl. Energy, vol. 209, no. October 2017, pp. 502-515, 2018. 